\title{
Children's Attitudes Toward Interaction with an Unfamiliar peer with Complex Communication Needs: Comparing High- and low-Technology Devices
}

\author{
Shakila Dada, Tenille Horn, Alecia Samuels \\ University of Pretoria \\ Ralf W. Schlosser \\ Northeastern University, Boston, MA
}

\begin{abstract}
Author note
Tenille Horn, Centre for Augmentative and Alternative Communication, University of Pretoria; Shakila Dada, Centre for Augmentative and Alternative Communication, University of Pretoria; Alecia Samuels, Centre for Augmentative and Alternative Communication, University of Pretoria; and Ralf W. Schlosser, Department of Speech-Language Pathology and Audiology, Northeastern University, Boston, USA, and Centre for Augmentative and Alternative Communication, University of Pretoria

The authors would like to thank the children, their families, and the school staff for making the study possible. This study was supported by University of Pretoria Postgraduate Research Bursary and the National Research Foundation Knowledge Interchange and Collaboration Grant (92953).

Correspondence regarding this article should be addressed to Shakila Dada, Centre for Augmentative and Alternative Communication, University of Pretoria, Pretoria, 0028. E-mail: shakila.dada@up.ac.za
\end{abstract}




\begin{abstract}
This study examined the attitudes of children with typical development towards an unfamiliar peer with complex communication needs using augmentative and alternative communication (AAC) systems. Specifically, the study aimed to compare attitudes when the peer used mobile technology (i.e., $\mathrm{iPad}^{1 \odot}$ ) with an AAC-specific application (Proloquo2 $\mathrm{Go}^{2^{\mathrm{TM}}}$ ) versus a lowtechnology communication board. A within-group crossover design was utilized involving 78 children. Half of the participants (i.e., Group 1) viewed Video 1 of an unfamiliar peer with complex communication needs in a scripted communication interaction using an iPad with Proloquo2Go followed by Video 2 of the same interaction using a communication board. The other half of the participants (Group 2) viewed these videos in the reverse sequence. The Communication Aid/Device Attitudinal Questionnaire (CADAQ) was completed after watching each video. Results indicated that both groups attitudes were more positive towards Video 1 (iPad with Prologuo2Go) on certain dimensions of the CADAQ. The results are discussed and recommendations for future research provided.
\end{abstract}

Keywords: Attitudes; Augmentative and Alternative Communication; Mobile technology; Low-Technology devices 
The South African Education policy has undergone a major paradigm shift post-apartheid in which the need to move away from a twofold (special and general) education system towards an education system that addresses the diverse needs of all learners (Lomofsky \& Lazarus, 2001) was acknowledged in policy (South African Government, 1996; Education White Paper 6, 2001). These policies state that children with disabilities, including those with complex communication needs, have the right to unrestrictive school environments.

Inclusive education, however, remains challenging in South Africa for a variety of reasons. A recent report (Human Rights Watch, 2015) found that many children with disabilities in schools face discriminatory practices which serve as barriers to receiving a quality education. The barriers include access to education, access to the same curriculum as children without disabilities, costs of education, increased vulnerability to violence and abusive practices, low quality of education and inadequately trained teachers and negative attitudes towards children with disability (Human Rights Watch, 2015).

Attitude has been defined as “.... an idea charged with emotion which predisposes a class of action to a particular class of social situations" (Triandis, 1971, p. 2). According to this definition, attitude comprises cognitive, affective and behavioural components (Eagly \& Chaiken, 1993; Nowicki \& Sandieson, 2002; Triandis, 1971). The cognitive component of an attitude refers to the beliefs, knowledge and expectations of an individual and it governs one's perception and behavior. It also determines an individual's overall emotional reaction (Triandis, 1971). The affective component of attitude expresses the motivational and emotional state that is created within an individual and the behavioural component of attitude includes the individual's behavior, action, or response towards his or her beliefs (Kuiper \& MacDonald, 1983). Most people try to maintain consistency between their attitudes and their behaviors (Hymel, 1986) and may typically interact with others who hold similar attitudes to their own (Beck,Thompson, Kosuwan \& Prochnow, 2010). This may encourage exhibiting behaviours that mirror the attitudes held through social pressure (Kraus 1995).

Attitudes are therefore learnt dispositions that direct feelings, thoughts and actions (Kim, Kim, Lee \& Park, 2015). Negative attitudes towards children with disability may impede their ability to fully participate in society (Hergenrather \& Rhodes, 2007). Understanding the attitudes of communication partners is deemed important and necessary for successful interaction (Beck et al., 2010). If communication partners have negative feelings about the individuals who use AAC, 
the interaction is less likely to be successful (Kim et al., 2015). Despite the complexities of attitudes, it has been found that attitudes can be trained and shifted to a more positive attitude towards children with disabilities (Moore \& Nettelbeck, 2013). Understanding and knowing the variables that influence attitudes may enable interventionists to manipulate the actions and reactions of typically developing children (Beck, Kingsbury, Neff, \& Dennis, 2000b;

Rosenbaum, Armstrong, \& King, 1988). Knowledge about attitudinal influences could mean better peer acceptance which, in turn, could encourage better inclusion of children with disabilities into mainstream school environments (Hyppa-Martin et al., 2016).

Attitude research towards individuals who use augmentative and alternative communication (AAC) was reviewed by McCarthy and Light (2005). The review highlights the need to understand attitudes towards individuals that use AAC in order to develop methods that are effective in changing negative attitudes and in exclusionary behaviors that ensue from this. Positive attitudes could therefore replace barriers and biases faced by people who use AAC with proper supports and expectations. Additionally, the review found that attitudes were influenced by a variety of factors including characteristics of those interacting with a person using AAC (e.g. their gender and previous experience of people with disabilities), characteristics of the person who uses AAC (e.g their competence with the AAC system) as well as the AAC system itself (low-tech versus high-tech systems). Females and individuals with previous experience of people with disabilities were reported to have more positive attitudes than males and those without previous experience. The AAC system by itself reportedly did not appear to influence attitudes independently but rather by an interaction with the factors mentioned above (McCarthy \& Light; 2005). Age was identified as a factor influencing individuals' attitudes towards a person that uses AAC with differences noted between Grade 3 versus Grade 5 children (Beck, Fritz, Keller, Dennis, 2000). Similarly less positive attitudes towards peers who use AAC were noted in adolescents as they age. No differences were found however between Grade 4 and Grade5 children (Beck, Bock, Thompson \& Kosuwan, 2002). The studies indicate that younger children may have more positive attitudes towards persons that use AAC versus their older counterparts and knowing about attitudinal influences on AAC devices could mean better peer acceptance and the development of friendships early in childhood.

Findings on the influence of the AAC system itself on attitudes toward individuals who 
use AAC have been varied (Beck \& Dennis; 1996; Beck et al., 2000; 2010; Blockberger et al., 1993; Dada \& Alant, 2002; Gorenflo \& Gorenflo, 1997). In most of the studies, individuals' attitudes regarding a person using AAC did not seem to be influenced by the AAC system itself (e.g., Beck \& Dennis, 1996; Beck et al., 2000; Beck et al., 2002; Blockberger et al., 1993). However, other researchers have reported that more positive attitudes were associated with individuals using SGDs than low-tech communication boards or books (Gorenflo \& Gorenflo, 1997; Lilienfeld \& Alant, 2002). To date, no research has reported more positive attitudes toward low tech communication boards without voice output when compared to SGDs (McCarthy \& Light, 2005). However, it should be noted that in the South Africa context lowtech communication boards are widely used and have numerous advantages of even greater availability, affordability, and the ability to be developed in the 11 official languages of the country when compared to SGDs.

In recent years, children who use AAC in South Africa and internationally have been exposed to general consumer-level mobile technologies (e.g. iPad, iPhone $\bigodot^{1}$ ), that have the potential to boost the social acceptance of high-tech AAC devices and applications (Abbot, Brown, Evett, Standen, \& Wright, 2011; McNaughton \& Light, 2013; Kaghora et al.,2013; Shane et al., 2012). Related to this potential for increased acceptance, children with disabilities were found to be more interested in devices that are trendy and fit in with them and their peers compared to devices that do not (Gonzales, Leroy, \& De Leo, 2009). It is therefore reasonable to hypothesize that the potential for increased social acceptance when using such general consumerlevel mobile technologies for AAC purposes might translate into favorable attitudes by communication partners. Yet not much is known about attitudes toward mobile non dedicated AAC technologies which are in harmony with mainstream technology (Hayhoe, 2012). It thus is an important area of research since attitudes have the potential to be an important variable facilitating the inclusion of children who use AAC. In addition to the potential for improved social acceptance, this shift towards the use of mobile technologies enhances affordability (Flores et al., 2012; Hayhoe, 2012; McNaughton \& Light, 2013), usefulness (Chappel, 2011; Hayhoe, 2012) and portability (Chappel, 2011; Flores et al., 2012; Hayhoe, 2012; Hu, 2011). These are all important considerations in a country like South Africa, where dedicated high-tech AAC devices are often unaffordable (Alant, 2007). Hence, there are contextual factors that further bolster the need to study the effects of these mobile technologies on attitudes. Given 
these advantages and the fact that low-tech communication boards might be viewed as the business-as-usual communication option in the South African context, it is highly appropriate to compare its effects to mobile technologies in terms of attitudes. There has been a paucity of studies that compared the effects of iPad based SGDs and low tech communication aids (Achmadi et al., 2015). To date, one study compared childrens' attitudes towards iPad based SGDs versus a non-electronic AAC system. They found that first graders' attitudes toward the peer did not vary significantly as a function of the type of AAC system (Hyppa-Martin, et al., 2016).

Therefore, this study aimed to compare the attitudes of primary schoolchildren with typical development towards an AAC user using two different types of AAC systems: a general consumer-level mobile technology device (iPad) with an AAC application (Proloquo2Go) and a low-tech communication board.

\section{Method}

\section{Research Design}

A within-group crossover design was utilized for this study. This design allows the use of a small sample size: it has lower variability, is more robust, and reduces carry-over effects (Wang \& Bakhai, 2006). In addition, by counterbalancing the order of exposure, the design enables the researchers to rule out order effects (Jones \& Kenward, 1989; Kuehl, 2000).

Two videos were developed for the purpose of this study. The first video (Video 1) depicted a scripted (supplemental file) communication interaction of an unfamiliar peer with complex communication needs using the mobile technology (i.e., iPad) with the Proloquo2Go AAC application whereas the second video (Video 2) depicted the same conversation and peer using a communication board. The Communication Aid/Device Attitudinal Questionnaire (CADAQ) was used as the measuring instrument (Lilienfeld \& Alant, 2002) and was completed by each group of participants after each viewing of the videos. Group 1 watched Video 1 followed by Video 2 and Group 2 watched Video 2 followed by Video 1.

\section{Participants}

Purposeful sampling was utilized in this study. A mainstream school in the Gauteng province of South Africa was identified for participation as it enrolled children with typical development who met the following criteria for inclusion: (a) a chronological age between 9;0 (years; months) and 12;11, (b) attend a school (for at least one year) in which English was the 
language of instruction, and (c) no prior experience with a child with a disability or who uses AAC.

Informed consent letters were initially sent to the parents of 160 potential participants. Of these, six parents did not consent to their child's participation in the study and 71 did not return the consent letters. A total of 83 parents eventually consented to their child's participation in the study. The data of three children had to be excluded because they had previous experience with a person with a disability and two were excluded as they failed to adequately complete the

CADAQ. Hence, complete data were available for 78 children. They were divided into two sub groups by means of paired randomization, with Group 1 consisting of 16 boys and 23 girls, and Group 2 comprising 19 boys and 20 girls.

\section{Materials}

Communication Aid/Device Attitudinal Questionnaire (CADAQ). The CADAQ was developed by Lilienfeld and Alant (2002) for 11 - 13 year olds. This measure requires that participants are able to complete the CADAQ independently and have adequate comprehension of the statements in the questionnaire. The construct validity of the CADAQ was established and is described by Lilienfeld and Alant (2002). The CADAQ comprises two trial items and 37 statements that cover three dimensions of attitudes, namely the (a) Affective/Behavioral (the feelings and intent to take action on these feelings by peers with typical development towards a child that uses AAC), (b) Cognitive/Belief (the beliefs of peers with typical development about a child with complex communication needs), and (c) Communicative Competence (the operational, strategic, linguistic and social competencies). The CADAQ makes use of a 5-point Likert scale from 5 (I strongly agree) to 1 (I strongly disagree). The Affective/Behavioural dimension of attitudes comprises 13 statements, for example, "I would worry if Grace sat next to me in class" and "I would like to talk to Grace." The cognitive/belief dimension comprises 11 statements, for example "I think Grace has many friends" or "Grace needs lots of help to tell a story" and the communication dimension comprises 13 statements, for example, "Grace could say exactly what she wanted to" and "Grace could not communicate quickly enough."

Videos. Two similar videos (each approximately $3 \mathrm{~min}$ in duration) which only differed on the type of AAC system used. Both videos featured the same scripted conversation between a communication partner and an unfamiliar peer with complex communication using AAC. Both 
videos start by showing the communication partner and the unfamiliar peer using AAC sitting at a table next to each other. The videos then focus on the AAC display and only the back of the unfamiliar peer is shown as she interacts with a female communication partner in a scripted conversation. The communication partner who is visible at the beginning of the videos is no longer visible as the videos proceeds. Video 1 displayed the iPad with the Proloquo2Go together with synthesized speech output, while Video 2 featured a communication board with the communication partner voicing the visual output selected by the unfamiliar peer using AAC.

Displays. The different settings used on the Proloquo2Go for the iPad were as follows: (a) Appearance: display style: grid; number of columns: seven; Display option: image and label; (b) Background color: white; label position: below image; multi-line table: on; (c) Qwerty Text option: ArialMT, 25pt; (d) Speech setting: speak as you type settings: all switched off; (e) Interaction settings: Auto-clear message: on; repeated tap: set on stop speech; repeated delay: none selected; (f) Keyboard button: grid keyboard and all view buttons: off; (g) Volume: high; (h) speech rate: slow; (i) Voice personalization: normal; (j) Grammar settings: grammar support: on; Trigger use: on hold; hold duration: $0.5 \mathrm{~s}$; use of double tap: switched off; advanced grammar option: on; and (k) Access method setting: no selections made.

A low-tech communication board display similar in content and size to the display of the iPad was utilized in this study. It consisted of a screenshot of the iPad display which was a QWERTY keyboard, with black letters on a white background pasted onto a black cardboard and matt laminated. The size of the communication board was $19.8 \mathrm{~cm} \times 14.9 \mathrm{~cm}$.

\section{Procedures}

Ethical approval to conduct the study was obtained from the relevant higher education authorities. Permission was obtained from the relevant education department and the school principal for the school at which the study was conducted. Consent was obtained from the parents of the potential participants, as well as from the participants themselves. Group 1 was called to the test venue (a classroom) where they were handed the letter of consent, a pencil and a CADAQ marked in accordance with the pre-coded number allocated to them to ensure confidentiality of data. The researcher introduced herself and obtained assent from the participants. The scripted instructions was then read to the participants prior to showing the video to the group. The instructions we as follows "We are now ready to start. You are about to watch a 4 minute video of Grace, a person with a disability, who is unable to speak. Grace does 
use other ways of communicating which you will see in two videos. After you have watched the first videos I will read out some questions and you will mark your answers in the booklet.

Thereafter we will have a short activity break and you will watch a second video with Grace using another way of communicating. You will also answer questions about that video."

They viewed Video 1 (video of the communication interaction of an unfamiliar peer with complex communication needs using the iPad with Proloquo2Go QWERTY display and speech output). After this the researcher read each statement on the CADAQ out aloud to the group. A pause of 10s followed to allow the participants to respond before the next statement was read. After completion of the first CADAQ, a game comprising of a few physical exercises was introduced to give the participants a 10-min break, without an opportunity to talk to each other. When the game was finished, the participants were seated again. They then viewed Video 2 (the video of the communication interaction of an unfamiliar peer with complex communication needs using the communication board), and thereafter completed the CADAQ, following the same procedures as for Video 1 . The researcher then collected the CADAQ and answered any questions that the participants may have had. Group 1 returned to their classrooms and Group 2 was requested to come to the test venue. The same procedure was followed for Group 2, with the only exception that they watched the videos in a reversed sequence (first Video 2 and then Video 1).

\section{Scoring and Reliability}

All of the statements in the CADAQ were scored from 1 to 5 depending on the statement. Positively worded statements were scored from 5 (I strongly agree) to 1 (I strongly disagree). Negatively worded statements were reverse-scored.

For the Affective/Behavioral dimensions, Cronbach Alpha coefficients for Video1 and Video 2 were $\alpha=0.87$ and $\alpha=0.87$, respectively; for the Cognitive/Belief dimension they were $\alpha=0.72$ and $\alpha=0.75$, respectively; and for the Communication Competence dimension they were $\alpha=0.82$ and $\alpha=0.77$ respectively. Internal consistency for this scale, based on the Cronbach Alpha coefficients, was $\geq 0.70$, which is satisfactory (Nunally, 1978).

\section{Results}

\section{Equivalence of Groups}

Table 1 presents the means, standard deviations for each group, age and $p$ value using the $t$ test to compare the two groups. No statistically significant difference $(p=0.66)$ between the 
Table 1: Mean Age of Each Group

\begin{tabular}{|c|c|c|c|}
\hline Group & Mean (months) & Standard deviation & $p$ value \\
\hline 1 & 131.36 & 9.63 & \multirow{2}{*}{0.66} \\
\hline 2 & 130.36 & 10.173 & \\
\hline
\end{tabular}

two groups was found for the age variable. Table 2 illustrates the gender, home language and number of years attending the school for the participants for each of the groups, and the $p$ values using Fisher's exact test to compare the two groups. Table 2 illustrates no statistically significant difference for the two groups regarding gender $(p=0.65)$, number of years at school $(p=0.09)$ or home language $(p=0.29)$ distribution. This indicates that the two groups were equivalent on these variables.

Table 2: Group Characteristics

\begin{tabular}{|c|c|c|c|c|}
\hline & & Group 1 & Group 2 & $p$ value \\
\hline \multirow[t]{2}{*}{ Gender } & Boys & $41.03 \%$ & $48.72 \%$ & \multirow[t]{2}{*}{0.65} \\
\hline & Girls & $58.97 \%$ & $51.28 \%$ & \\
\hline Number of years & 1 & $5.13 \%$ & $0.00 \%$ & \multirow[t]{8}{*}{0.09} \\
\hline \multirow[t]{7}{*}{ attending school } & 2 & $12.82 \%$ & $10.26 \%$ & \\
\hline & 3 & $2.56 \%$ & $17.95 \%$ & \\
\hline & 4 & $12.82 \%$ & $25.64 \%$ & \\
\hline & 4.5 & $2.56 \%$ & $0.00 \%$ & \\
\hline & 5 & $43.59 \%$ & $35.90 \%$ & \\
\hline & 6 & $17.95 \%$ & $10.26 \%$ & \\
\hline & 7 & $2.56 \%$ & $0.00 \%$ & \\
\hline \multirow[t]{10}{*}{ Home language } & Afrikaans & $5.13 \%$ & $0.00 \%$ & \multirow[t]{10}{*}{0.29} \\
\hline & English & $58.97 \%$ & $41.03 \%$ & \\
\hline & isiNdebele & $2.56 \%$ & $0.00 \%$ & \\
\hline & isiXhosa & $12.82 \%$ & $12.82 \%$ & \\
\hline & isiZulu & $5.13 \%$ & $15.38 \%$ & \\
\hline & Sepedi & $5.13 \%$ & $10.26 \%$ & \\
\hline & Sesotho & $0.00 \%$ & $2.56 \%$ & \\
\hline & Setswana & $5.13 \%$ & $12.82 \%$ & \\
\hline & Siswati & $2.56 \%$ & $0.00 \%$ & \\
\hline & Xitsonga & $2.56 \%$ & $5.13 \%$ & \\
\hline
\end{tabular}

\section{Order Effect}

A nested ANOVA was performed to determine the presence of an order effect, in other words whether the sequence in which the two videos were watched by the participants influenced their attitudes. There were no statistically significant order effects for the Affective/ Behavioral dimension $(p=0.05)$ as well as the Cognitive dimension $(\mathrm{p}=0.08)$ with a statistically significant effect for Communicative Competence $(p=0.03)$.

\section{Within-group Comparisons}

Within-group and gender comparisons could be made between Video 1 (the unfamiliar peer using iPad with Proloquo2Go application) and Video 2 (the unfamiliar peer using a communication board). Table 3 illustrates for each dimension of the CADAQ the mean, standard deviation and paired $t$ test for Group 1 and Group 2, respectively. 
Running head: CHILDREN'S ATTTITUDES TOWARDS AAC DEVICES

Table 3: Within-Group and Gender Comparisons for Each Video

\begin{tabular}{|c|c|c|c|c|c|c|c|c|}
\hline \multirow[b]{3}{*}{ Group 1} & \multirow{3}{*}{$\begin{array}{c}\text { Video } \\
\text { Dimension } \\
\text { Affective/Behavioural dimension }\end{array}$} & \multicolumn{2}{|c|}{ iPad with Proloquo2Go } & \multicolumn{2}{|c|}{ Communication board } & \multirow[b]{2}{*}{$p$ value } & \multirow{2}{*}{\multicolumn{2}{|c|}{ Effect size }} \\
\hline & & \multirow{2}{*}{$\begin{array}{c}\text { Mean } \\
3.97\end{array}$} & \multirow{2}{*}{$\begin{array}{c}\begin{array}{c}\text { Standard } \\
\text { deviation }\end{array} \\
0.67\end{array}$} & \multirow{2}{*}{$\begin{array}{c}\text { Mean } \\
3.83\end{array}$} & \multirow{2}{*}{$\begin{array}{c}\begin{array}{c}\text { Standard } \\
\text { deviation }\end{array} \\
0.77\end{array}$} & & & \\
\hline & & & & & & $0.02 *$ & 0.19 & small \\
\hline & Cognitive/Belief dimension & 3.07 & 0.57 & 3.02 & 0.75 & 0.48 & 0.06 & small \\
\hline & $\begin{array}{l}\text { Communicative competence } \\
\text { dimension }\end{array}$ & 3.61 & 0.62 & 3.26 & 0.68 & $<0.0001^{*}$ & 0.51 & $\begin{array}{l}\text { mediu } \\
\mathrm{m}\end{array}$ \\
\hline \multirow[t]{3}{*}{ Group 2} & Affective/Behavioural dimension & 4.19 & 0.55 & 4.13 & 0.55 & 0.33 & 0.11 & small \\
\hline & Cognitive/Belief dimension & 3.36 & 0.60 & 3.17 & 0.48 & $0.04 *$ & 0.31 & small \\
\hline & $\begin{array}{l}\text { Communicative competence } \\
\text { dimension }\end{array}$ & 3.80 & 0.64 & 3.57 & 0.51 & $0.0039 *$ & 0.37 & small \\
\hline \multirow[t]{3}{*}{ Boys } & Affective/Behavioural dimension & 3.93 & 0.64 & 3.87 & 0.63 & 0.43 & 0.09 & small \\
\hline & Cognitive/Belief dimension & 3.18 & 0.55 & 3.14 & 0.57 & 0.58 & 0.07 & small \\
\hline & $\begin{array}{l}\text { Communicative competence } \\
\text { dimension }\end{array}$ & 3.66 & 0.62 & 3.49 & 0.65 & $0.02 *$ & 0.27 & small \\
\hline \multirow[t]{3}{*}{ Girls } & Affective/Behavioural dimension & 4.21 & 0.58 & 4.06 & 0.69 & $0.01 *$ & 0.22 & small \\
\hline & Cognitive/Belief dimension & 3.24 & 0.65 & 3.06 & 0.69 & $0.03^{*}$ & 0.26 & small \\
\hline & $\begin{array}{l}\text { Communicative competence } \\
\text { dimension }\end{array}$ & 3.75 & 0.64 & 3.36 & 0.59 & $<0.0001^{*}$ & 0.60 & $\begin{array}{l}\text { mediu } \\
\mathrm{m}\end{array}$ \\
\hline
\end{tabular}

Table 3 shows that for Group 1 a statistically significant difference was found in the Affective/ Behavioral dimension $(p=0.02)$ as well as in the Communicative Competence dimension $(p<0.0001)$ - in both cases with a small effect size in favor for Video 1. However, no statistically significant difference was evident for the Cognitive/Belief dimension $(p=0.48)$.

This indicates that Group 1 had significantly more favourable attitudes towards Video 1 than Video 2 with respect to the Affective/Behavioural and Communicative Competence dimensions.

For Group 2, a statistically significant difference was found in favor of video 1 over video 2 for the Cognitive/Belief dimension $(p=0.04)$ as well as for the Communicative Competence dimension $(p=0.0039)$ - in the case of both dimensions with a small effect size.

The Affective/Behavioural dimension $(p=0.32)$ revealed no statistically significant difference.

Hence, Group 2 had significantly more favourable attitudes toward Video 1 than Video 2 in respect of the Cognitive/Belief $(p=0.04)$ and Communicative Competence dimension ( $\mathrm{p}=$ $0.004)$.

\section{Gender Effects}

Table 3 illustrates that for boys there was a statistically significant difference with a small effect size between the two videos with respect of the Communicative Competence dimension $(p$ $=0.0151)$. However, in the case of the girls a statistically significant difference was found for all three dimensions - (i.e., for the Affective/Behavioural dimension) $(p=0.43)$ and the Cognitive/Belief dimension $(p=0.58)-$ both with a small effect size - and for the Communicative Competence dimension $(p=<0.0001)$ with a medium effect size. This indicates that the girls who participated in our study had more favourable attitudes regarding all three dimensions for video 1 than for video 2 . 


\section{Discussion}

This study aimed to compare the attitudes of typically developing children aged 9 to 12 years of age towards an AAC user when using two different types of AAC systems: a general consumer-level mobile technology (iPad) with an AAC application (Proloquo2Go) versus a lowtech communication board. The current study demonstrates that the unfamiliar peer was perceived more favorably when using the iPad with Proloquo2Go as compared to the communication board by both groups of participants.

Unique to this study is that a within group design was used and equivalence of groups in terms of age, number of years attending school and home language was ensured. Group 1 was more positive toward the use of the iPad in the Affective/Behavioral and Communicative Competence dimensions, whereas Group 2 was more positive toward the iPad in the Cognitive/Belief and Communicative Competence dimensions. This statistically significant difference is noteworthy as several previous studies did not find any statistically significant difference in attitudes in terms of the the type of AAC devices implemented (Beck \& Dennis, 1996; Beck et al., 2000a; 2000b; 2002; Blockberger et al., 1993; Gorenflo \& Gorenflo, 1997; Hyppa-Martin, 2016) though different attitudinal scales were used. The exception was, however, the Lilienfeld and Alant (2002) study, which found that children with typical development displayed a more positive attitude towards a high-tech dedicated AAC device when compared to a low-tech communication board across all three dimensions of the CADAQ. The greatest variances were found within the Communicative Competence dimension.

A positive attitude displayed towards high technology is supported by Bedrosian, Haog, and McCoy (2004), who found that technology has the ability to shape perceptions of communication competence. In previous research, it was found that children with typical development displayed a more positive attitude towards children with disabilities if they are perceived to be communicatively more competent (Beck \& Dennis, 1996; Beck et al., 2002, 2010; Blockberger et al., 1993; King et al., 1989; Schlosser, 2003). Therefore, an underlying principle of intervention is that greater individual competence in the use of communication aids is likely to contribute to more frequent and diverse opportunities for participating in everyday discourse (Clarke et al., 2011).

The results from this study are congruent with these findings, since for both groups of participants more positive attitudes were found on the CADAQ's Communicative Competence 
dimension for the unfamiliar peer with complex communication needs when using the iPad with Proloquo2Go application. This could indicate that the use of general consumer-level mobile technologies with AAC applications makes it more likely typically developing children perceive unfamiliar peers with complex communication needs as communicatively competent. According to Light (1989) and Light and McNaughton (2014), communicative competence is reflected when a person with disabilities is viewed as being competent or functional in daily communication.

Discovering that the attitudes of children with typical development tend to be more positive towards the iPad with Proloquo2Go may have positive implications for children who use general consumer-level mobile technologies with AAC applications. Positive attitudes may motivate and enhance social interaction with peers (McNaughton \& Light, 2013), although that remains to be studied.

The role that gender plays in children's attitudes towards children who use AAC has been well documented in recent years (Beck \& Dennis, 1996; Beck et al., 2000a, b, 2002, 2010; Blockberger et al., 1993; Lilienfeld \& Alant, 2002; Hyppa-Martin et al., 2016) and the findings reveal that girls generally have more positive attitudes towards children that use AAC than do boys. The results obtained in our research study confirm this as well. The boys who participated in our study were also found to be more positive on the Communicative Competence dimension when viewing the video with the iPad compared to the video with the communication board.

\section{Conclusions and Recommendations for Future Research}

This study should be seen as a first step in understanding attitudes towards the use of general consumer-level mobile technologies with AAC applications. The most important finding of this study was that, in various dimensions of the CADAQ, children with typical development displayed a more positive attitude towards an unfamiliar peer with complex communication needs who used a mobile technology with an AAC application than towards that same peer who used a communication board. Serious consideration should therefore be given to the use of mobile AAC technologies like the iPad with speech output and AAC applications to facilitate the process of including children with complex communication needs into inclusive school settings. As Lilienfeld and Alant (2002) noted, an AAC device plays only a small part in promoting the inclusion of children with complex communication needs into schools; however, a more positive attitude displayed by peers with typical development towards AAC devices can hold numerous 
advantages for social interaction and inclusion. The gender differences found in this study need to be considered in developing awareness programs to facilitate the inclusion of children with complex communication needs. Greater consideration, empathy and a more positive attitude in boys' perceptions of children with complex communication needs should be developed.

The current study does however have some limitations. The generalizability of the findings is limited by the small sample size along with limited age range of $(9 ; 00-12 ; 11$ years) and therefore the conclusions cannot be generalized to all children with typical development. Finally, the results are limited to English-speaking participants from a specific geographical area (i.e., South Africa). Recommendations for future research include a replication of the study with participants who have limited exposure and access to technology, and studies where a mobile technology is compared with a high-tech dedicated AAC device.

\section{References}

Abbott, C., Brown, D., Evett, L., Standen, P. \& Wright, J. (2011) Learning difference and digital technologies: a literature review of research involving children and young people using assistive technologies 2007-2010. http://www.kcl.ac.uk/sspp/departments/education/research/crestem/steg/recentproj/assisti vetech.aspx.

Achmadi, D., van der Meer, L., Sigafoos, J., Lancioni, G. E., O’Reilly, M. F., Lang, R., ... \& McLay, L. (2015). Undergraduates' perceptions of three augmentative and alternative communication modes. Developmental Neurorehabilitation, 18, 22-25. http://dx.doi.org/10.3109/17518423.2014.962767

Alant, E. (2007, August 14). Covering the world of communication sciences and disorders: Training and intervention in South Africa. The ASHA Leader. Retrieved from http://www.asha.org/Publications/leader/2007/070814/f070814a1.htm

Beck, A. R., Bock, S., Thompson, J. R., \& Kosuwan, K. (2002). Influence of communicative competence and augmentative and alternative communication technique on children's attitudes toward a peer who uses AAC. Augmentative and Alternative Communication, 18, pp. 217-227. doi: 10.1080/07434610212331281301

Beck, A. R., \& Dennis, M. (1996). Attitudes of children toward a similar-aged child who uses augmentative communication. Augmentative and Alternative Communication, 12, 78-87. 
Beck, A. R., Fritz, H., Keller, A., \& Dennis, M. (2000a). Attitudes of school-aged children toward their peers who use augmentative and alternative communication. Augmentative and Alternative Communication, 16, 13-26. doi: 10.1080/07434610012331278874

Beck, A. R., Kingsbury, K., Neff, A., \& Dennis, M. (2000b). Influence of length of augmented messages on children's attitudes toward peers who use augmentative and alternative communication. Augmentative and Alternative Communication, 16, 239-249. doi: $10.1080 / 07434610012331279094$

Beck, A.R., Thompson, J.R., Kosuwan, K., \& Prochnow, J. M. (2010). The development and utilization of a scale to measure adolescents' attitudes toward peers who use Augmentative and Alternative Communication (AAC) devices. Journal of Speech, Language, and Hearing Research 53, pp. 572-587.

doi: 10.1044/1092-4388(2009/07-0140)

Bedrosian, J. L., Haog, L. A., \& McCoy, K. F. (2004) Relevance and speed of messages delivery trade-offs in augmentative and alternative communication. Journal of Speech, Language, and Hearing Research, 46, 800-817.

Blockberger, S., Armstrong, R. W., O’Connor, A., \& Freeman, R. (1993). Children's attitudes towards a nonspeaking child using various augmentative and alternative communication techniques. Augmentative and Alternative Communication, 9, 243-250. doi:

$10.1080 / 07434619312331276661$

Chappel, D. (2011). The evolution of augmentative communication and the importance of alternate access. Perspectives on Augmentative and Alternative Communication,20, 3437. doi:10.1044/aac20.1.34

Clarke, M. T., Newton, C., Griffiths, T., Price, K., Lysley, A., \& Petrides, K. V. (2011). Factors associated with the participation of children with complex communication needs. Research in Developmental Disabilities, 32, 774-780. doi: 10.1016/j.ridd.2010.11.002

Dada, S., \& Alant, E. (2002). A comparative study of the attitudes of teachers at special and educationally inclusive schools towards learners with little of no functional speech using communication devices. South African Journal of Education, 22(3), pp. 213-218.

Eagly, A. H., \& Chaiken, S. (1993). The psychology of attitudes. Fort Worth, TX: Harcourt 
Brace Javanovich.

Education White Paper 6 (2001). Special needs education: Building an Inclusive education and system. Pretoria, Department of Education.

Flores, M., Musgrove, K., Renner, S., Hinton, V., Strozier, S., Franklin, S., \& Hil, D. (2012). A comparison of communication using the Apple iPad@ and a picture-based system. Augmentative and Alternative Communication, 28,74-84. doi: $10.3109 / 07434618.2011 .644579$

Gonzales, C., Leroy, G., \& De Leo, G. (2009). Augmentative and alternative communication technologies. In M.M. Chunha, A. Tavaras, A. Simoes (Eds.), Handbook of research on developments in e-health and telemedicine: technologies and social perspective. Medical Information Sciences (pp. 1-16). Hershey,PA: IGI Global

Gorenflo, D. W., \& Gorenflo, C. W. (1997). Effects of synthetic speech, gender, and perceived similarity on attitudes towards the augmented communicator. AAC Augmentative and Alternative Communication,13, 87-91. doi: 10.1080/07434629712331277878

Hayhoe, S. (2012). Using an iPad as an assistive device to improve technical literacy: Trial usage with an Emirati student. In: S. Dowling (Ed.), eLearning in action: Opening up learning. Abu-Dhabi, UAE: Educational Technology Series. HCT Press.

Hergenrather, K., \& Rhodes, S. (2007). Exploring undergraduate student attitudes toward persons with disabilities application of the disability social relationship scale. Rehabilitation Counseling Bulletin, 50, 66-75.

http://dx.doi.org/10.1177/00343552070500020501

Hu, W. (2011). Math that moves: School embraces the iPad. The New York Times, 4.

Human Rights Watch (2015). “Complicit in exclusion”: South Africa's failure to guarantee an inclusive education for children with disabilities. Retrieved from https://www.hrw.org/report/2015/08/18/complicit-exclusion/south-africas-failureguarantee-inclusive-education-children

Hyppa-Martin, J., Collins, D., Chen, M., Amundson, C., Timinski, K., \& Mizuko, M. (2016). Comparing First Graders’ Attitudes and Preferences Toward a Peer Using an iPad®Based Speech-Generating Device and a Non-Electronic AAC System. Augmentative and Alternative Communication, 32: 94-104, doi: 10.3109/07434618.2016.1146332

Hymel, S. (1986). Interpretations of peer behavior: Affective bias in childhood and adolescence. 
Child Development, 57: 431-445 http://dx.doi.org/10.1111/j.1467-8624.1986.tb00043.x

Jones, B., \& Kenward, M. G. (1989). Design and analysis of cross-over trials: Monographs on statistics and applied probability. New Delhi, London: Thomson Press (India) Ltd.

Kagohara, D. M., van der Meer, L., Ramdoss, S., O’Reilly, M. F., Lancioni, G. E., Davis, T. N., ... \& Green, V. A. (2013). Using iPods $®$ and iPads $®$ in teaching programs for individuals with developmental disabilities: A systematic review. Research in Developmental Disabilities, 34, 147-156. http://dx.doi.org/10.1016/j.ridd.2012.07.027

Kim, J. R., Kim, Y. T., Lee, H. J., \& Park, E. H. (2015). Influence of message error type on Korean adults' attitudes toward an individual who uses augmentative and alternative communication. Augmentative and Alternative Communication, 31, 159-169.

http://dx.doi.org/10.3109/07434618.2015.1008569

King, S. M., Rosenbaum, P., Armstrong, R. W., \& Milner, R. (1989). An epidemiological study of children's attitudes toward disability. Developmental Medicine and Child Neurology, 237-245. doi: 10.1111/j.1469-8749.1989.tb03984.x

Kraus, S. J. (1995). Attitudes and the prediction of behavior: A meta-analysis of the empirical literature. Personality and social psychology bulletin, 21(1), 58-75. http://dx.doi.org/10.1177/0146167295211007

Kuehl, R. O. (2000). Design of experiments: Statistical principles of research design and analysis. (2nd ed.). Pacific Grove, California: Duxbury Press, Brooks/Cole Publishing Co.

Kuiper, N. A., \& MacDonald, M. R. (1983). Reason, emotion, and cognitive therapy. Clinical Psychology Review, 3, 297-316. doi: 10.1002/casp.849

Light, J. (1989). Toward a definition of communicative competence for individuals using augmentative and alternative communication systems. Augmentative and Alternative Communication, 5, 137-144. doi: 10.1080/07434618912331275126

Light, J., \& McNaughton, D. (2014). Communication competence for individuals who require augmentative and alternative communication. Augmentative and Alternative Communication, 30, 1-18. doi: 10.3109/07434618.2014.885080

Lilienfeld, M., \& Alant, E. (2002). Attitudes of children toward an unfamiliar peer using an AAC device with and without voice output. Augmentative and Alternative Communication, 18, 
Running head: CHILDREN'S ATTTITUDES TOWARDS AAC DEVICES

91-101. doi: 10.1080/07434610212331281191

Lomofsky, L. \& Lazarus, S. (2001). South Africa: First steps in the development of an inclusive education system. Cambridge Journal of Education, 31(3), pp.303-317. doi: $10.1080 / 03057640120086585$

McCarthy, J. \& Light, J. (2005). Attitudes toward individuals who use augmentative and alternative communication: Research review. Augmentative and Alternative Communication, 21, 41-55. doi: 10.1080/07434610410001699753

McNaughton, D., \& Light, J. (2013). The iPad and mobile technology revolution: Benefits and challenges for individuals who require augmentative and alternative communication. Augmentative and Alternative Communication, 29, 107-116. doi: $0.3109 / 07434618.2013 .784930$

Moore, D. \& Nettelbeck, T. (2013). Effect of short-term disability awareness training on attitudes of adolescent schoolboys toward persons with a disability. Journal of Intellectual and Developmental Disability. 38(3), pp. 223-231. doi: $10.3109 / 13668250.2013 .790532$

Nowicki, E. A., \& Sandieson, R. (2002). A meta-analysis of school-aged children's attitudes towards a person with physical and intellectual disabilities. International Journal of Disability, Development and Education, 49, 287-313. doi:10.1080/1034912022000007270

Nunally, J. C. (1978). Psychometric theory. (2nd ed.). New York: McGraw-Hill.

Rosenbaum, P. L., Armstrong, R. W., \& King, S. M. (1988). Determinants of children's attitudes towards disability: A review of evidence. Children's Health Care, 17, 32-39. doi:

10.1207/s15326888chc1701_5Saxe, R., Carey, S., \& Kanwisher, N. (2004). Understanding other minds: Linking developmental psychology and functional neuroimaging. Annual Review Psychology, 87-124. doi: 10.1146/annurev.psych.55.090902.142044

Shane, H. C., Blackstone, S., Vanderheiden, G., Williams, M., \& DeRuyter, F. (2012). Using AAC technology to access the world. Assistive technology, 24, 3-13.

South African Government (1996). The Constitution of the Republic of South Africa, Chapter 2: Bill of Rights. Parliament. 
Running head: CHILDREN'S ATTTITUDES TOWARDS AAC DEVICES

Triandis, H. C. (1971). Attitude and attitude change. New York, NY: Wiley.

Voeltz, L. M. (1980). Children's attitudes toward handicapped peers. American Journal of Mental Deficiency, 84, pp. 455-464.

Wang, D., \& Bakhai, A. (2006). Clinical trials: A practical guide to design, analysis and reporting. London: Remetica.

\section{Endnotes}

${ }^{1}$ The iPad and iPhone are devices available from Apple Inc., Cupertino, CA.

http://www.apple.com

${ }^{2}$ Proloquo $2 \mathrm{Go}^{\mathrm{TM}}$ is a symbol-supported communication app available from Assistive Ware,

Amsterdam, Netherlands. http://www.assistiveware.com/product/proloquo2go 